\title{
ESTUDOS DE INTERAÇÃO DE PROTEÍNAS COM NANOPARTÍCULAS VIA TÉCNICAS ESPECTROSCÓPICAS
}

\author{
Marcela J. R. de Barros ${ }^{1 *}$, Yarima Sánches García ${ }^{1}$, Jorge L. Neves ${ }^{1}$ \\ ${ }^{1}$ Laboratório de Química Biológica, dQF - UFPE \\ *marcela.jacinta@hotmail.com
}

\begin{abstract}
INTRODUÇÃO
As proteínas são polímeros constituídos fundamentalmente por aminoácidos, cuja cadeia lateral é a responsável por forças estabilizadoras oriundas de interações fracas (ligações de hidrogê nio, hidrofóbicas, eletrostáticas, etc.) que mantêm as suas estruturas conformacionais enoveladas. ${ }^{[1]}$

Grande parte dos processos que ocorrem em organismos vivos acontece a partir da interação entre proteínas e ligantes. Por exemplo, a transmissão de sinal mediada pelo ligante através de complementaridade molecular é essencial para todos os processos de um organismo vivo, sendo estas interações químicas de reconhecimento biológico, ocorrem a nível molecular. ${ }^{[1]}$

A Albumina é uma proteína carreadora muito utilizada em estudos biomiméticos de interação com diferentes ligantes por ser uma das mais abundante no plasma sanguíneo, além de ser responsável por diversas funções biológicas, como transporte e metabolismo de ligantes exógenos e endógenos.

A grande estabilidade e disponibilidade da albumina de soro bovino faz dela uma proteína de grande utilização, além da grande similaridade com a albumina humana. ${ }^{[2]}$

O uso de técnicas espectroscópicas, como por exemplo, UV-Vis e fluorescência, no detalhamento molecular da interação entre materiais e biomoléculas vêm recebendo especial atenção. Estes estudos são efetuados em meio fisiológico, mimetizando sistemas biológicos realisticamente, além de preservar as amostras analisadas. ${ }^{[3 ; 4]}$

Existem diversas possibilidades para a utilização destas técnicas com a finalidade de determinar interações entre ligante e proteí na, principalmente na determinação da constante de ligação de complexos entre ligantes e biomoléculas, e no fornecimento de outras informações úteis do ponto de vista estrutural. ${ }^{[4]}$

Neste contexto, é proposto neste trabalho a síntese e caracterizaç ão de materiais com base em nanopartículas de carbono, assim como a interação destes biomateriais com proteínas relevantes para o metabolismo celular, através de técnicas bioquímicas e espectroscópicas, assim como avaliação citotóxica destas partí culas frente a células tumorais.
\end{abstract}

\section{MATERIAIS E MÉTODOS}

- Síntese de nanopartículas:

A metodologia de síntese foi realizada de acordo com García, Y. S., 2016. ${ }^{[4]}$

- $\quad$ Caracterização do material sintetizado:

Após o preparo das nanoparticulas, as amostras foram sujeitas a microscopia eletrônica de transmissão. A fim de serem estudadas as interações destes produtos com proteína, foi usado um aparelho de RMN de $400 \mathrm{MHz}$, visando estudar o efeito das interações nos tempos de relaxação e posterior avaliação das constantes de interação.

Foram utilizados também outros métodos espectroscópicos, como Espectroscopia de UV-Visível, onde os dados obtidos podem certificar a interação entre nanopartículas e a proteína, e a Espectroscopia de Fluorescência, a fim de determinar constantes de ligação e a natureza das interações.

- Avaliação citotóxica do material obtido

Para determinação da citotoxicidade, uma suspensão celular de 105 células/mL será preparada em meio adaptado para cada linhagem celular. A suspensão foi distribuída em placas de cultura com 96 poços. As placas serão incubadas a $37 \circ \mathrm{C}$ em estufa (Sedas, Milão-Itália), com atmosfera úmida enriquecida com 5Ao fial deste período, o meio de cultura, juntamente com o excesso de MTT, foram aspirados e em seguida adicionado o dimetilsulfóxido (DMSO) a cada poço para a dissolução dos cristais de formazan. 0 método do MTT baseia-se na capacidade que células vivas possuem em reduzir o sal tetrazólio, de cor amarela, a formazan insolúvel, de cor púrpura que precipita graças à ação da enzima mitocondrial succinildesidrogenase, ativa apenas em células vivas. A leitura ó ptica foi feita em leitor automático de placas a $595 \mathrm{~nm}$.

\section{RESULTADOS E DISCUSSÃO}

Inicialmente, foram realizados testes de extração das nanopartí culas em soluções de etanol e água destilada. Ao utilizar maior fraç ão de etanol foram obtidos melhores resultados, desde que se trabalhasse com o devido cuidado de, após a extração, secar e ressuspender em água destilada, para evitar a desnaturação das proteínas durante os estudos de interação. Essa desnaturação ocasionaria a precipitação das proteínas devido ao rompimento das interações fracas. ${ }^{[1]}$

O tamanho e a morfologia dos sistemas sintetizados foram analisados utilizando-se a microscopia eletrônica de transmissão (MET), que podem ajudar a definir o tamanho e a morfologia das nanopartículas sintetizadas. ${ }^{[6]}$ Como mostra a Figura 1, os tamanhos são em média da ordem de $10 \mathrm{~nm}$. 


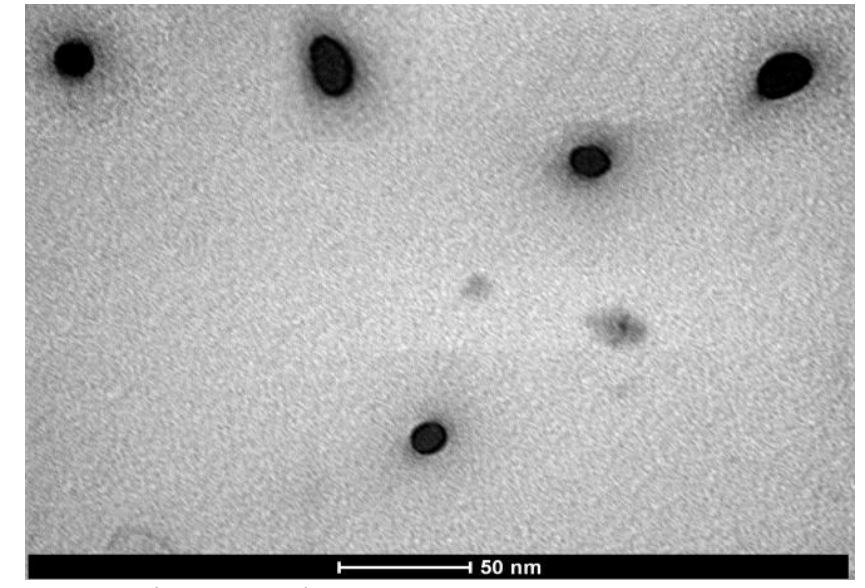

Figura 1. MET das NP sintetizadas.

Para a realização dos estudos de interação, inicialmente utilizamos a técnica de espectroscopia de absorção UV-Vis. Desta forma, foi possível detectar que não houve mudanças estruturais na proteína estudada, ao variar-se a concentração de nanopartículas adicionadas a elas, pois não acontece o deslocamento no comprimento de onda do pico de absorção. Outra observação foi o decréscimo da absorbância no espectro UV-Vis obtido a partir da titulação das nanopartículas, como mostra a Figura 2, o que indica que há a formação de um complexo entre BSA e Mn@Cdots. ${ }^{[4]}$

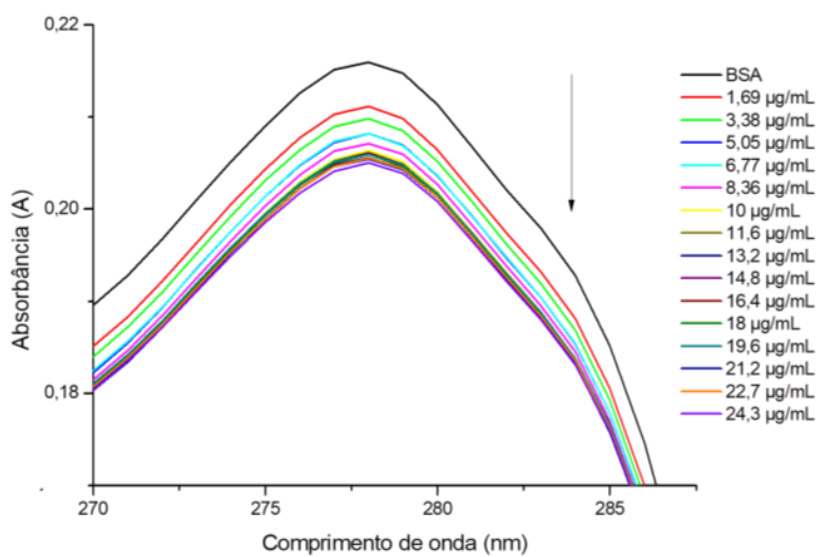

Figura 2. Espectro UV-Vis da BSA, $5 \mu \mathrm{M}$, que mostra o decréscimo da absorbância da proteína com a adição de nanopartículas ente 1,69 e 24,3 $\mu \mathrm{g} / \mathrm{mL}$.

Para avaliar formação do possível complexo utilizamos uma técnica de RMN que é a medida do tempo de relaxação, figura 3. A ligação entre a nanopartículas e a proteína causa mudanças nos tempos de relaxação T1 do complexo, e a partir deles pode ser obtida a constante de ligação. ${ }^{[7]} \mathrm{O}$ valor de T1 é obtido pela regressão não linear a função $M(t)=M 0\left(1-2 e^{-t / T 1}\right)$, onde $M(0)$ e a intensidade do sinal no tempo $t=0$ (ver Figura 3 ). Estes valores foram calculados $e$ são mostrados na Figura 4 em função da concentração das nanopartículas. A partir deste gráfico foi possível determinar a constante de ligação: $K_{a}=5,788 \cdot 10^{6} \mathrm{M}^{-1}$.

Para complementar estes resultados, já que a espectroscopia de RMN possui baixa sensititividade ${ }^{[8]}$, fez-se uso da técnica de fluorescência que apresenta limites de detecção baixos e apresenta grande sensibilidade a mudanças na estrutura e no ambiente de proteínas. ${ }^{[9]}$

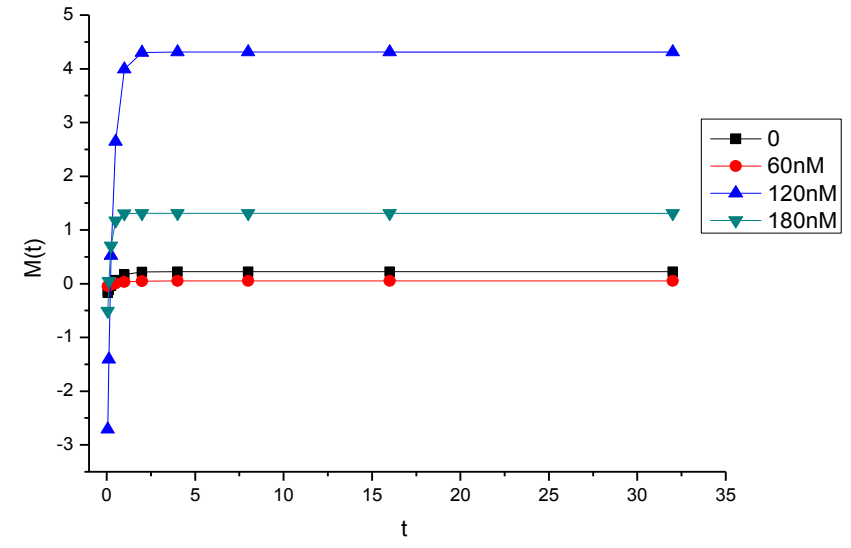

Figura 3. Comportamentos do sinal em função do tempo.

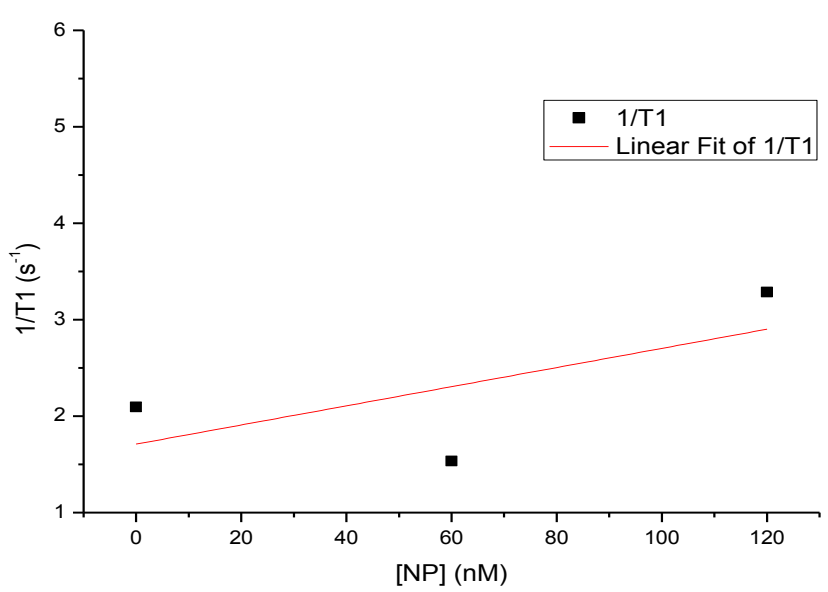

Figura 4. Gráfico de 1/T10bservado vs Concentração de nanopartículas em nM.

Deste modo, as interações que ocorrem entre a proteína e as nanopartículas também podem ser avaliadas por espectroscopia de fluorescência. A fluorescência é um processo fotoluminescente, onde moléculas ou átomos têm seus elétrons de valência excitados por absorção de radiação eletromagnética, em um comprimento de onda específico, chamado de comprimento de onda de excitação. Quando estas espécies voltam ao seu estado fundamental, liberam o excesso de energia na forma de fótons, geralmente de comprimentos de onda maiores que o de excitação, chamado de comprimento de onda de fluorescência. ${ }^{[10]}$

Nos experimentos realizados foi utilizado o método que mede a quantidade de quenching (supressão) de fluorescência, ou seja, a redução da intensidade da fluorescência da proteína durante a interação com as nanopartículas, que pode ocorrer por um mecanismo de supressão dinâmica (colisional) ou supressão está tica, dentre outros vários mecanismos. No mecanismo dinâmico, o fluoróforo, que é a espécie que apresenta a fluorescência, quando no estado excitado são desativados após interagir com o supressor, chamado também de quencher. Já no mecanismo estático, o fluoró foro interage com o supressor formando um complexo que não tem atividade fluorescente. Assim, não há emissão de fóton quando o complexo absorve luz, voltando imediatamente ao estado fundamental. ${ }^{[9]}$

Para as proteínas, este método faz uso de sua fluorescência natural de proteínas, que são oriundas dos aminoácidos fluorescentes tirosina, triptofano e fenilalanina ${ }^{[10 ; 11]}$, com estruturas mostradas na Figura 6. A maioria dos compostos que fluorescem são aromá ticos e alguns poucos alifáticos com ligações duplas alternadas. Os aminoácidos citados acima são os que possuem maior atividade de 
fluorescência por suas características estruturais, como grupos funcionais aromáticos.<smiles>N[C@@H](Cc1ccccc1)C(=O)O</smiles><smiles>N[C@@H](Cc1ccc(Cl)cc1)C(=O)O</smiles><smiles>NC(Cc1c[nH]c2ccccc12)C(=O)O</smiles>

Figura 6. Estrutura dos principais aminoácidos responsáveis pela fluorescência da proteí na, em sequência, fenilalanina, tirosina e triptofano. ${ }^{[12]}$

Durante a análise, usou-se um intervalo de comprimento de onda entre 300 e $450 \mathrm{~nm}$, visto que a emissão máxima de fluorescência da BSA é em aproximadamente $350 \mathrm{~nm}$, com excitação em 290 nm. ${ }^{[9]}$

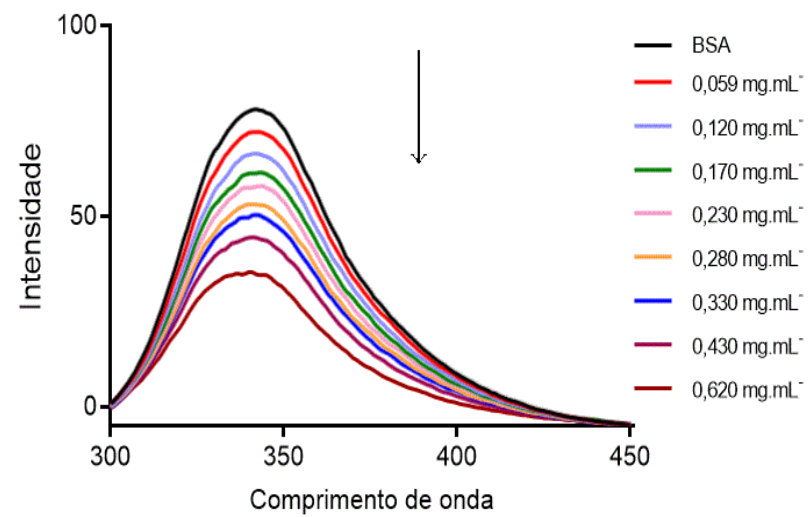

Figura 7. Espectro de fluorescência da BSA $5 \mu \mathrm{M}$, durante a titulação de Mn@Cdots que mostra o decréscimo da intensidade fluorescência da proteína com a adição de nanopartí culas, com concentração variando ente 59 e $620 \mu \mathrm{g} / \mathrm{mL}$.

Como mostra a Figura 7, a intensidade de fluorescência da proteína foi modificada devido à adição das nanopartículas, diminuindo regularmente com o aumento da concentração de Mn@Cdots. Isto indica a ocorrência de um quenching na fluorescência da BSA devido à interação com as nanopartículas. A redução da intensidade de fluorescência é descrita pela equação 1 , chamada de equação de Stern-Volmer: ${ }^{[9]}$

$\frac{\mathrm{F}_{0}}{\mathrm{~F}}=1+\mathrm{K}_{\mathrm{SV}}[\mathrm{Q}]$

Onde, $F_{0}$ e $F$ representam a intensidade da fluorescência na ausê ncia e na presença do quencher, respectivamente. $K_{s v}$ é a constante Stern-Volmer de quenching, em que $K_{s v}$ representa $k_{q} \tau_{0}$, constante de supressão bimolecular e tempo de vida sem a supressão. E [Q] é a concentração do supressor (quencher), neste caso, as nanopartículas (NP).

Geralmente, é possível diferenciar os processos de supressão dinâ mica e estática de dois modos. 0 primeiro é através da dependê ncia do processo com a variação da temperatura. Se, ao aumentar a temperatura, a inclinação da reta $\left(\mathrm{K}_{\mathrm{sv}}\right)$ também aumentar, tratase de um processo dinâmico, se ele diminuir, estático. ${ }^{[9]}$ Esta implicação se deve ao fato de que, o aumento da temperatura aumenta a energia cinética média dos fluoróforos, culminando com uma maior probabilidade de colidir com o supressor. Desta forma, num processo dinâmico, o sinal de fluorescência decai mais intensamente, fazendo com que $F \ll F_{0}$ e, por conseguinte, $K_{s v}$ aumenta. Já num processo estático, como mais fluoróforos formarã o complexo não fluorescente com o quencher, $\mathrm{F}$ vai ficando cada vez mais próximo de $\mathrm{F}_{0}$, logo $\mathrm{K}_{\mathrm{sv}}$ diminui. $\mathrm{O}$ segundo modo seria por meio da medida do tempo de vida da fluorescência. Na supressão estática, a formação do complexo remove uma fração da espécie que fluoresce, e então apenas a fluorescências dos fluoróforos não complexados é observada, e o tempo de vida $\tau$ é igual ao $\tau_{0}$. Do contrário, $\tau_{0} / \tau=F_{0} / F$.

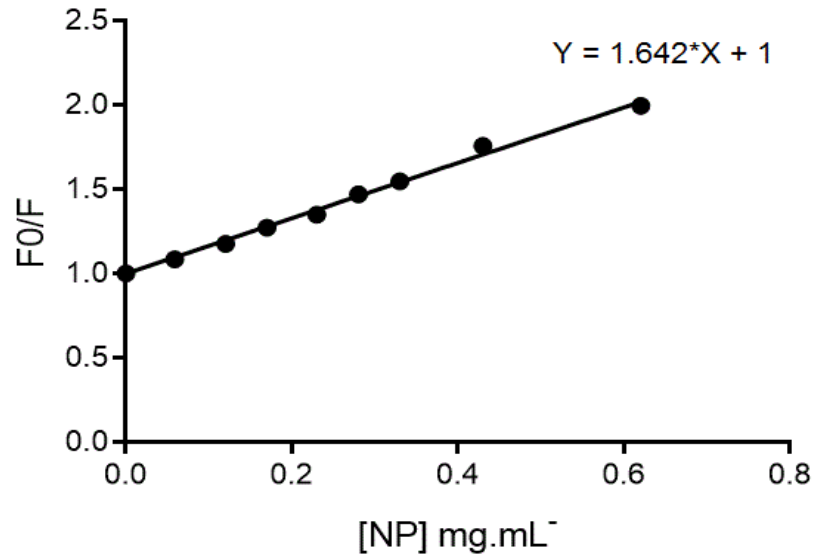

Figura 8. Gráfico Stern-Volmer para quenching da intensidade da proteína BSA pela titulação das nanopartículas Mn@Cdots (NP). $\mathrm{K}_{\mathrm{SV}}=287,3 \times 10^{3} \mathrm{M}^{-1}$, ou $1,642 \mathrm{~mL} \cdot \mathrm{mg}^{-1}$.

Analisando a equação de Stern-Volmer e o gráfico da Figura 8, nos casos em que a curva seja uma reta, a inclinação desta reta é proporcional à taxa de supressão, $\mathrm{K}_{\mathrm{sv}}$, que pode estar ligada a formação de complexos ou a um processo de colisão. Os resultados mostram uma grande linearidade, indicando a possibilidade de as nanopartículas e a proteína formarem complexos. ${ }^{[9]}$

Assumindo que um processo de supressão estática ocorra, e que existam sítios de ligação na proteína que sejam independentes, o número de sítios ligantes $(n)$ e a constante de ligação $\left(K_{B}\right)$ podem ser obtidos a partir da equação $2 .{ }^{[3]}$

$\log \frac{\mathrm{F}_{0}-\mathrm{F}}{\mathrm{F}}=\log \mathrm{K}_{\mathrm{B}}+\operatorname{nlog}[\mathrm{Q}]$

A partir daí, obteve-se os parâmetros de interesse da equação $2, n$ e $K_{B}$ a partir do gráfico apresentado na Figura 9, onde $n=1,079$ e $K_{B}=0,311 \cdot 10^{6} \mathrm{M}^{-1}$, tendo mesma ordem de grandeza da constante encontrada a partir da análise com a técnica de RMN.

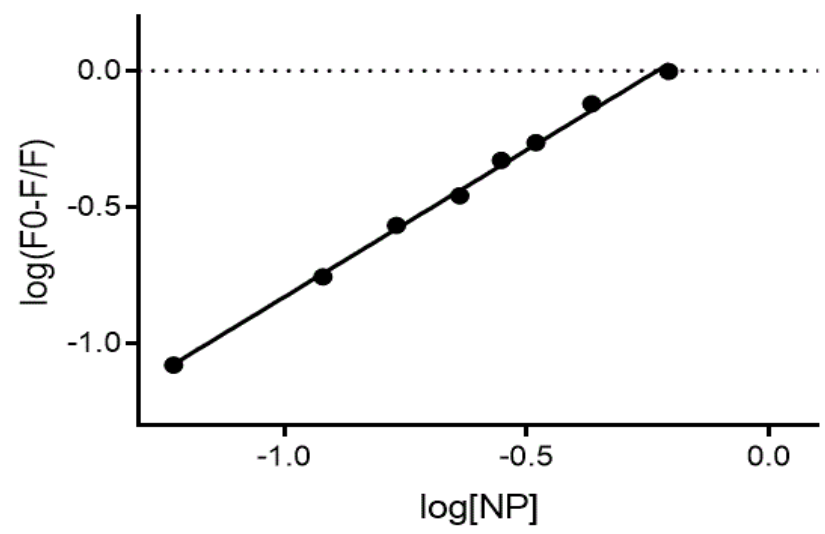

Figura 9. Gráfico Log $x \log$ representado pela equação 2 , com $n=1,079$ e $K_{B}=311,7 \times 10^{3}$ $M^{-1}$.

Os estudos de citotoxicidade foram realizados com células epiteliais de adenocarcinoma pulmonar a549, escolhidas por serem mais facilmente cultivaveis. ${ }^{[13]}$ Os resultados indicam que as nanopartículas sintetizadas não apresentam toxicidade mensurável até a concentração de aproximadamente $0,4 \mathrm{mg} \cdot \mathrm{mL}^{-1}$, como mostra a Figura 10, possibilitando os sistemas aqui apresentados serem usados para aplicações biológicas. 


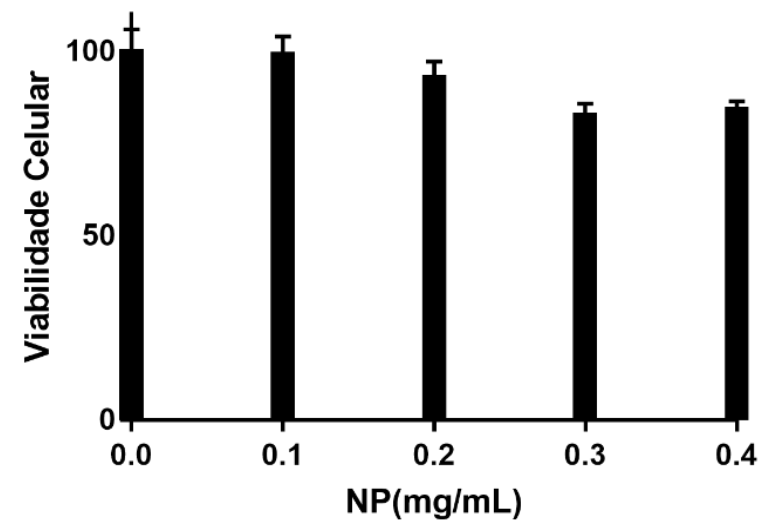

Figura 10. Estudo de citotoxicidade nas nanopartículas Mn@Cdots, mostrando que não apresentam toxicidade até $0,4 \mathrm{mg} \cdot \mathrm{mL}^{-1}$.

\section{CONCLUSÕES}

Neste trabalho, a interação entre a proteína plasmática BSA e as nanoparticulas de carbono e manganês foi estudada por técnicas espectroscópica, como UV-vis, RMN, e também fluorescência. Os resultados das análises com UV-vis mostram decréscimo da absorbâ ncia da proteína, com a adição das nanopartículas, confirmando a formação de um complexo entre nanopartículas e BSA. A partir dos estudos com RMN, foi possível detectar mudanças nos tempos de relaxação T1 a medida que diferentes concentrações de nanopartí culas foram adicionadas, e deles pôde ser obtida a constante de ligação. $\mathrm{Na}$ análise da fluorescência intrínseca da proteína, teve-se como resultado o quenching da fluorescência da proteína devido à adição das nanopartículas, indicando a possibilidade de as nanopartículas e a proteína formarem complexos. A proporção de proteínas e nanopartículas no complexo pôde ser obtida, juntamente com a constante de ligação, tendo mesma ordem de grandeza da constante encontrada a partir da análise com a té cnica de RMN. E, as nanopartículas sintetizadas não apresentaram toxicidade em concentrações consideradas altas, possibilitando sejam adequados para aplicações biológicas. Desta forma, visamos aprofundar estudos de interação entre a proteína BSA e algumas moléculas orgânicas.

\section{REFERÊNCIAS}

[1] FRANCISCO JUNIOR, WILMO ERNESTO; FRANCISCO, WELINGTON. Porteínas: Hidrólise, Precipitação e um tema para o ensino de Quí mica. Química Nova Na Escola, São Paulo, n. 24, p.12-16, nov. 2006. Trimestral.

[2] PETERS JR., T.; All About Albumin; Biochemistry, Genetics and Medical Applications/Ligand Binding by Albumin, Academic Press: San Diego, 1995.

[3] XIE, J.; DONG, H.; YU, Y., CAO, S. Inhibitory effect of synthetic aromatic heterocycle thiosemicarbazone derivates on mushroom tyrosinase: Insights from fluorescence, ${ }^{1} \mathrm{H}$ NMR titration and molecular docking studies. Food Chemistry, 190 (2016), 709-716.

[4] MOHAMMADZADEH-AGHDASH, H.; DOLATABADI, J. E. N.; DEHGHAN, P.; BARZEGAR, A. Multi-spectroscopic and molecular modeling studies of bovine serum albumin interaction with sodium acetate food addctive. Food Chemistry, 228 (2017) 265-269.

[5] GARCÍA, Y. S. Estudos de formação de proteínas corona em nanosistemas de contraste a base de carbono e íons metálicos $\mathrm{Mn2+}$, Fe 3+ e Eu3+. Departamento de química fundamental, Programa de pós-graduação em Química - Exame de qualificação, Universidade Federal de Pernambuco, 2016.

[6] Microscopia Eletrônica de Transmissão (MET), CETENE. Disponí vel em:
< http://www.cetene.gov.br/pdf/met.pdf >, acesso em 23/05/17. [7] F. Ni, Prog. NMR Spectrosc. 26 (1994) 517.

[8] SANTOS, MAIARA DA S.; COLNAGO, LUIZ ALBERTO. Validação de método quantitativo por RMN de ${ }^{1} \mathrm{H}$ para análises de formulações farmacêuticas. Quím. Nova, São Paulo, v. 36, n. 2, p. 324-330, 2013.

[9] SILVA FERREIRA, ERNANDO. Interação da albumina do soro bovino (BSA) com substratos sintéticos. Departamento de Física e Matemática, Faculdade de Filosofia, Ciências e Letras de Ribeirão Preto, Programa de Pós-Graduação em Física Aplicada à Medicina e Biologia, Universidade de São Paulo, Dissertação de Mestrado, 2009.

[10] SKOOG, D.A., HOLLER, F.J., NIEMAN, T.A. Princípios de Análise Instrumental. 5. ed. Rio de Janeiro: Bookman, 2002.

[11] LAKOWICZ, J.R., Principles of Fluorescence Spectroscopy. 2nd ed. 1999: Cambridge university press. 185.

[12] NELSON, D.L. e COX, M.M. Lenhinger: Princípios de Bioquí mica. 3a ed. Trad. A.A. Simões e W.R.N. Lodi. São Paulo: Sarvier, 2002. VOET, D.; VOET, J.G

[13] Academia de Ciência e Tecnologia - São José do Rio Preto: Biologia do câncer. Disponível em:

<http://www.ciencianews.com.br/index. php/publicacoes/artigoscientificos/biologia-do-cancer/> Acesso: 08/11/17 